\title{
Behaviour and stress in three breeds of laying hens kept in the same environment
}

\author{
I. Rozempolska-Rucińska1, A. Czech², K. Kasperek', G. Zięba' \& A. Ziemiańska"\# \\ ${ }_{1}^{1}$ Institute of Biological Basis of Animal Production, University of Life Sciences in Lublin, Akademicka 13, 20-950 Lublin, \\ Poland \\ 2 Department of Biochemistry and Toxicology, University of Life Sciences in Lublin, Akademicka 13, 20-950 Lublin, \\ Poland
}

(Received 7 October 2019; Accepted 30 January 2020; First published online 25 April 2020)
Copyright resides with the authors in terms of the Creative Commons Attribution 4.0 South African License. See: http://creativecommons.org/licenses/by/4.0/za
Condition of use: The user may copy, distribute, transmit and adapt the work, but must recognize the authors and the South African Journal of Animal Science.

\begin{abstract}
The aim of the study was to determine whether birds of different breeds, with different preferences for environmental elements and kept in identical conditions, would exhibit different behaviour and stress levels. The research material consisted of 50 laying hens of the Green-legged partridge $(\mathrm{Zk})$, Polbar $(\mathrm{Pb})$, and Leghorn $(\mathrm{Lg})$ breeds. The birds were provided with identical environmental conditions. They were kept on litter in separate boxes, with 25 individuals of one breed per box, in the same building. An open field test was used in determining the behaviour of the birds. Levels of cortisol in serum and corticosterone in feathers were evaluated, and haematological and biochemical analyses of blood were performed. Leghorns proved to be a highly excitable and active breed whose needs cannot be fully satisfied in the standard conditions of large farms. Based on a differential leukocyte count, their hyperactivity was associated with increased stress. The Green-legged partridge exhibited the lowest stress levels. Birds kept in the same environmental conditions were found to differ significantly in the level of stress, probably because of differences in their behavioural needs and the possibilities of satisfying them. To reduce stress levels and improve the welfare of hens, it is necessary to verify their preferences first. Stress indicators are elevated in highly excitable birds, and the conditions on large farms are not conducive to meeting their behavioural needs.
\end{abstract}

Keywords: behavioural test, blood indices, corticosterone, laying hens

\#Corresponding author: agnieszka.kozak@up.lublin.pl

\section{Introduction}

Increasing awareness among consumers of animal products and scientific discoveries in the field of ethology have led to modifications to and improvement of the rearing conditions and welfare of animals. Hens receive considerable attention in behavioural research because of the problems of feather pecking, housing conditions, diet, and cognitive abilities. To ensure the wellbeing of animals, various measures are taken to enrich their environment and improve living conditions (Zimmerman, 2011). However, chickens of different breeds have been shown to differ not only in their degree of excitability and emotional reactivity, but in their preferences for elements that enrich the environment (Kozak et al., 2019a). Depending on breed, birds explore objects, devoting different amounts of time to this activity. Differences between breeds are also reflected in features such as the time and manner of exploration of the environment and the number of objects examined (Kozak et al., 2019b).

Behavioural patterns depend not only on the living environment and experiences of birds, but also on genetic determinants, environmental conditions during embryonic development, and epigenetic effects (Janczak et al., 2007; Lindqvist et al., 2007). Therefore, to ensure the welfare of hens, modifications of the environment should be considered that allow reflection of characteristic and important elements of the breed's behaviour (Kozak et al., 2019a, b, c). However, no recommendations have ever been formulated for different conditions of rearing in different breeds of laying hens. Hence, the question arises as to how birds cope with this problem. Do birds adapt to the same environment despite behavioural differences, showing a high degree of plasticity, or do some breeds show increased stress? In an attempt to answer these questions, the research carried out by these authors has been expanded (Kozak et al., 2019a, b, c). 
The aim of the study was to determine whether birds of different breeds that prefer different environment-enrichment elements and are kept in identical conditions would exhibit differences in behaviour and in the levels of stress.

\section{Material and Methods}

All procedures during the research were approved by the Second Local Ethics Committee for Animal Testing at the University of Life Sciences in Lublin, Poland (Approval No. 69/2017 of 28 September 2017). The birds were inspected by a veterinarian before the study to confirm that their health could not influence the test results.

This research was conducted on three breeds of laying hens, namely Green-legged partridge (Zk), Polbar ( $\mathrm{Pb}$ ), and Leghorn ( $\mathrm{Lg})$ (Figure 1). These breeds had been the subject of earlier research (Kozak et al., 2019a). Green-legged partridge is a native Polish breed that is often found on organic farms. These hens are well adapted to the conditions of extensive free-range farming. Polbar was created by mating Greenlegged partridge hens with Plymouth Rock cocks. The breed features of $\mathrm{Pb}$ chickens became fixed in the 1950s. Both breeds (Zk and $\mathrm{Pb})$ are kept in closed populations that do not undergo selection, as they are included in a genetic resource's conservation programme. Leghorn, which is one of the most popular layer hen breeds, is especially adapted to intensive breeding and is subjected to intensive selection. The research material consisted of 150 laying hens, including $50 \mathrm{Zk}, 50 \mathrm{~Pb}$ and $50 \mathrm{Lg}$. All birds came from the same brood and were 33 weeks old at the time of the behavioural study. All breeds were kept in one building to ensure uniform environmental conditions, in six separate pens on litter, each with 25 hens of one breed. Each pen had a density of $0.3 \mathrm{~m}^{2} /$ individual bird (Journal of Laws, 2003).
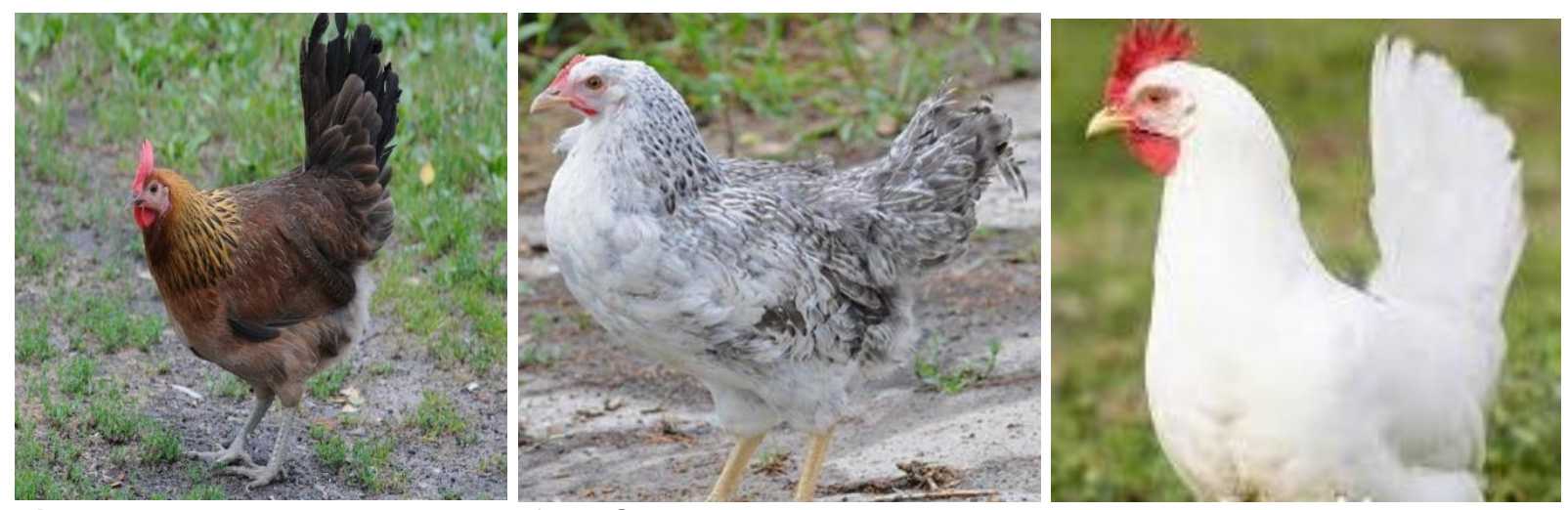

Figure 1 Representative images of the Green-legged partridge, Polbar, and Leghorn laying hens

The hens were selected randomly from the breeding flock and placed in the pens two months before the beginning of the experiment. The pens were equipped with eight nests, two linear feeders $(2 \times 2)$, and five nipple drinkers. They were exposed to light for 16 hours a day. Behavioural tests were carried out between $08 \mathrm{~h} 00$ and $15 \mathrm{~h} 00$ over six days using a $1.25 \times 1.25 \mathrm{~m}$ observation pen that was created specially for the modified open-field test (MOFT). The birds had contact with the researcher every day. Each bird was tested once. Each day, 25 birds from one pen were tested. All chickens were evaluated to determine their behaviour in environmentally enriched conditions (Rodenburg et al., 2004; Kozak et al., 2019a). The test was modified with the addition of these environment-enrichment elements: a container with water, one with commercial feed, another with commercial feed supplemented with finely cut straw and insect larvae, a sandpit, a mirror, and a box resembling a nest (Figure 2) (Kozak et al., 2019c). None of the objects was known to the birds. The placement of the special observation pen excluded visual and auditory contact between the birds. The floor in the observation pen was divided into 25 squares of $25 \times 25 \mathrm{~cm}$ each. Above the pen, a camera recorded the behaviour of each bird throughout the test. A detailed description of and the rationale behind the use of the MOFT test are provided in Kozak et al. (2019c). 


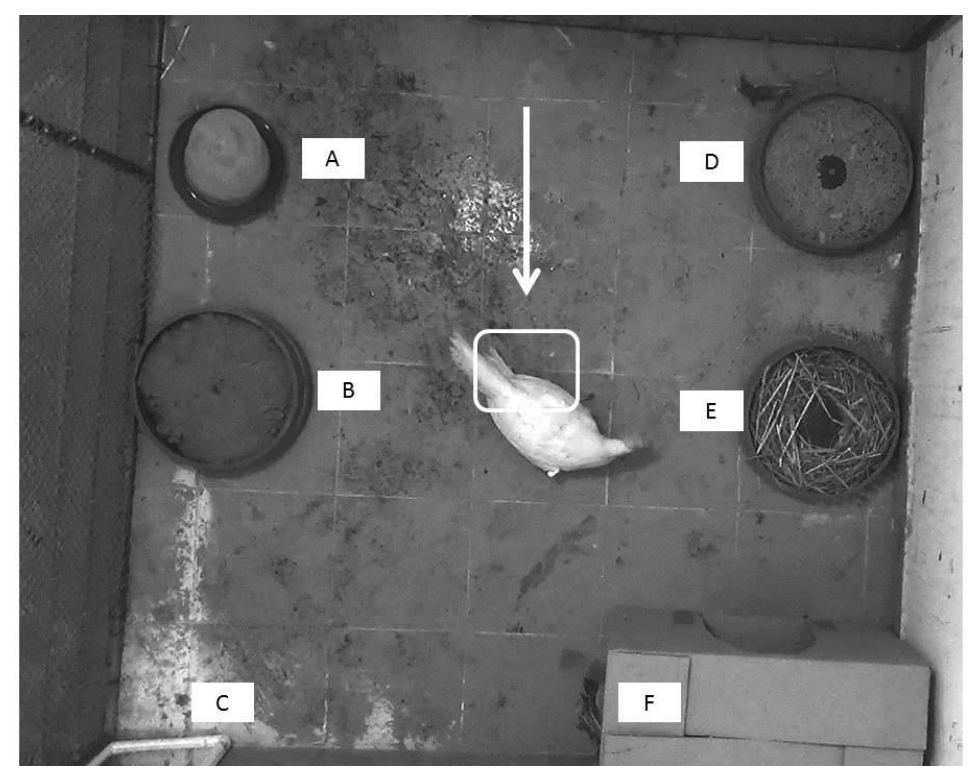

Figure 2 Layout of pen used to conduct a modified open field behavior test for laying hens A: water container, B: sandpit, C: mirror, D: commercial feed, E: enriched feed, F: shelter

The birds were brought into the observation pen individually by the experimenter and left in the middle. They were recorded individually for 600 seconds. The analysis of the video included the following indicators: i) time before beginning exploration (seconds), that is, time between placement of the hen on the floor in the experimental pen and the beginning of moving; ii) exploration time(s): time the hen spent exploring and showing interest in the enrichment elements; iii) number of objects explored $(n)$ : number of objects approached by the hen during the test and interest expressed in the object; and iv) number of squares crossed $(n)$ by the hen during the test. Crossing denoted standing inside the square. If a bird did not begin to explore during the entire study period (600 seconds), a value of 600 s was assigned.

Parameters that were assigned during the analysis included the occurrence of physiological and behavioural activities that reflected reactivity, that is, defecating, shaking, preening, and vocalising. Each of the behaviours was assessed separately on a binary scale in which 0 denotes the absence of the activity and 1 denotes occurrence. Such types of behaviour may be associated with stress, agitation, relief of emotional tension, and expectation of positive events (Spruijt et al., 1992; Manning \& Dawkins, 1992; Berthelsen \& Hansen, 1999; Hansen \& Berthelsen, 2000; Zimmerman et al., 2011); therefore, they were included in the observations

To determine the relationship between the behaviour of birds and their level of susceptibility to stress, a biochemical blood test was carried out to assess stress level indicators. The blood was collected after an eight-hour fasting period with unrestricted access to drinking water. At 33 weeks old, blood was drawn from the wing vein of 10 hens from each group by a veterinarian. The blood was collected five days after the MOFT test.

The blood was placed in a refrigerator $\left(-4^{\circ} \mathrm{C}\right)$ and transported to the laboratory (about 1 hour). The analyses were performed immediately after the samples had been delivered.

Each blood sample was collected in a test tube containing disodium salt of ethylenediaminetetraacetic acid (EDTA) as an anticoagulant (Oyewale, 1992). Whole blood samples were collected for analyses from the brachial vein to determine the haematocrit $(\mathrm{Ht})$ level with the microhaematocrit method, the haemoglobin $(\mathrm{Hb})$ content with Drabkin's method, and the erythrocyte count with the manual chamber technique after dilution in a Natt-Herrick solution. The haemoglobin concentration was determined spectrophotometrically after lysis of erythrocytes and release of $\mathrm{Hb}$ (Feldman et al. 2000). The percentage composition of white blood cells (leukograms) was determined. That is, the numbers of heterophils (HET), lymphocytes (LYM), monocytes (MON), eosinophils (EOS), and basophils (BAS) by Pappenheim staining (Romeis, 1989) of blood smears, and the ratio of heterophils to lymphocytes were calculated $(H: L)$.

For analysis of biochemical parameters and minerals, blood was collected into test tubes without an anticoagulant. After centrifugation, the level of cortisol and the contents of sodium, potassium, and chlorine were determined in the blood serum. Cortisol was tested by enhanced chemiluminescence on an IMMULITE 2000 XPi SIEMENS analyser. Sodium (Na), potassium (K), and chloride (Cl) were determined by direct 
potentiometry on an Erba Mannheim XL-640 biochemical analyser.

The serum level of lysozyme (classified as a protective barrier in the body) was measured with the turbidimetric method, in which a continuous rate reaction under conditions of optimum substrate concentration, $\mathrm{pH}$, and ionic strength is measured. This is based on the spectrophotometric measurement of lysis of Micrococcus lysodeikticus (Siwicki \& Anderson, 1993).

The corticosterone level in feathers was determined according to the method modified by Bortolotti et al. (2008). Briefly, the second quill of the first row was taken from the left wing of each bird. One feather was collected from each hen. The whole feather was removed after blood collection. The feathers were washed in isopropyl alcohol, dried for 24 hours in free air, and weighed. Vanes were cut into pieces and placed in 2 $\mathrm{mL}$ Eppendorf tubes, and $1.5 \mathrm{~mL}$ of methanol was added to each tube. The samples were ground with steel balls in a homogenizer (TissueLyser II, Qiagen, Venlo, Netherlands). The supernatant was filtered on a syringe filter ( $\phi 0.2 \mu \mathrm{L}$ Millipore Millex-GN) and the level of corticosterone was determined using a chicken corticosterone ELISA kit (fine test) according to the manufacturer's procedure.

Because the behavioural traits did not have a normal distribution, the data were initially subjected to rank transformation. Statistical calculations of these traits were performed by one-way model, considering the influence of the breed. The calculations were made using general linear models (GLM) in SAS 9.4 software (SAS Institute, Cary, NC, USA). The significance of differences between means was determined using Tukey's test.

\section{Results and Discussion}

The birds of the three breeds began to explore their surroundings at similar time points, and the means did not differ significantly. However, the analysis of their behaviour in the MOFT test revealed that during the 600-second test with the same time point of undertaking exploration, $\mathrm{Lg}$ birds explored a significantly higher number of objects in a shorter time than $\mathrm{Zk}$ and $\mathrm{Pb}$ hens (Table 1). Leghorn hens also moved intensively around the experimental pen, as evidenced by the number of squares crossed, which was higher than in the other two breeds. Thirty of the 150 birds did not explore their surroundings, including $9 \mathrm{Zk}$, $11 \mathrm{~PB}$, and $10 \mathrm{Lg}$. The preliminary analysis showed no significant effect of breed on undertaking activity by the birds.

Table 1 Behavioural characteristics of Leghorn, Polbar, and Green-legged partridge chicken breeds during the modified open-field test

\begin{tabular}{lcccc}
\hline Breed & $\begin{array}{c}\text { Time before } \\
\text { beginning } \\
\text { exploration }(\mathrm{s})\end{array}$ & $\begin{array}{c}\text { Mean duration of } \\
\text { exploration of the } \\
\text { object }(\mathrm{s})\end{array}$ & $\begin{array}{c}\text { Number of objects } \\
\text { explored }(\mathrm{n})\end{array}$ & $\begin{array}{c}\text { Number of squares } \\
\text { crossed }(\mathrm{n})\end{array}$ \\
\hline Leghorn & $74.2 \pm 6.1$ & $65.6^{\mathrm{a}} \pm 4.1$ & $2.4^{\mathrm{a}} \pm 0.2$ & $25.3^{\mathrm{A}} \pm 2.6$ \\
Polbar & $80.7 \pm 6.1$ & $80.0^{\mathrm{b}} \pm 4.1$ & $1.6^{\mathrm{b}} \pm 0.2$ & $5.0^{\mathrm{B}} \pm 2.6^{2}$ \\
Green-legged partridge & $71.6 \pm 6.1$ & $80.4^{\mathrm{b}} \pm 4.1$ & $1.5^{\mathrm{b}} \pm 0.2$ & $6.2^{\mathrm{B}} \pm 2.6^{2}$
\end{tabular}

a, b; A, B Within a column, means with a common superscript did not differ at $P=0.05$ and 0.001 , respectively

Leghorn chickens were more excitable than the other breeds (Table 2). They shook, defecated, and exhibited preening behaviour more often than $\mathrm{Pb}$ and $\mathrm{Zk}$, while $\mathrm{Pb}$ and $\mathrm{Lg}$ vocalised more often than $\mathrm{Zk}$. The probability of occurrence of these behaviours was higher in $\mathrm{Lg}$ than in $\mathrm{Zk}$ and $\mathrm{Pb}$. These differences were statistically significant.

Table 3 presents means $( \pm S E)$ of measurements used to determine the stress levels in the hens. There were no differences in the serum level of cortisol, but the level of corticosterone in the feathers was significantly lower in $\mathrm{Zk}$ than in $\mathrm{Pb}$. No differences were found in the corticosterone level between $\mathrm{Lg}$ and the other breeds. 
Table 2 Probability of physiological and behavioural activities of the Leghorn Polbar and Green-legged partridge chicken breeds during the modified open-field test

\begin{tabular}{lcccc}
\hline Breed & Vocalisation & Preening & Defecation & Shaking \\
\hline Leghorn & $0.4^{\mathrm{B}} \pm 0.1$ & $0.6^{\mathrm{A}} \pm 0.1$ & $0.8^{\mathrm{A}} \pm 0.04$ & $0.6^{\mathrm{A}} \pm 0.1$ \\
Polbar & $0.3^{\mathrm{B}} \pm 0.1$ & $0.3^{\mathrm{B}} \pm 0.1$ & $0.1^{\mathrm{B}} \pm 0.04$ & $0.2^{\mathrm{B}} \pm 0.1$ \\
Green-legged partridge & $0.1^{\mathrm{A}} \pm 0.1$ & $0.2^{\mathrm{B}} \pm 0.1$ & $0.2^{\mathrm{B}} \pm 0.04$ & $0.1^{\mathrm{B}} \pm 0.1^{1}$
\end{tabular}

A, B Within a column, means with a common superscript did not differ at $P=0.001$

Table 3 Levels of measurements from blood of Leghorn, Polbar and Green-legged partridge laying hens that were used as indicators of stress

\begin{tabular}{|c|c|c|c|}
\hline \multirow{2}{*}{ Measurement } & \multicolumn{3}{|c|}{ Breed } \\
\hline & Green-legged partridge & Polbar & Leghorn \\
\hline Serum cortisol, $\mu \mathrm{g} / \mathrm{dL}$ & $1.27 \pm 0.03$ & $1.27 \pm 0.02$ & $1.34 \pm 0.02$ \\
\hline Corticosterone in feathers, $\mathrm{ng} / \mathrm{mL}$ & $3.97^{b} \pm 0.17$ & $4.50^{\mathrm{a}} \pm 0.19$ & $4.29^{a b} \pm 0.21$ \\
\hline Lysozyme, mg/L & $0.988^{B} \pm 0.02$ & $0.797^{A} \pm 0.02$ & $0.737^{A} \pm 0.02$ \\
\hline Leukocytes, $10^{9} / \mathrm{L}$ & $14.4^{\mathrm{B}} \pm 0.8$ & $15.5^{\mathrm{B}} \pm 0.8$ & $23.7^{\mathrm{A}} \pm 0.8$ \\
\hline Lymphocytes (L), \% & $68.86^{c} \pm 1.4$ & $59.50^{B} \pm 1.4$ & $47.75^{\mathrm{A}} \pm 1.3$ \\
\hline Monocytes, \% & $8.29^{c} \pm 0.70$ & $4.25^{\mathrm{B}} \pm 0.6$ & $17.00^{A} \pm 0.6$ \\
\hline Heterophils $(\mathrm{H}), \%$ & $22.29^{B} \pm 1.30$ & $35.75^{A} \pm 1.2$ & $33.75^{A} \pm 1.2$ \\
\hline Eosinophils, \% & $0.14^{B} \pm 0.10$ & $0.13^{B} \pm 0.1$ & $0.75^{A} \pm 0.1$ \\
\hline Basophils, \% & $0.43 \pm 0.30$ & $0.38 \pm 0.2$ & $0.75 \pm 0.2$ \\
\hline $\mathrm{H}: \mathrm{L}$ ratio & $0.32^{c} \pm 0.01$ & $0.60^{B} \pm 0.01$ & $0.71^{\mathrm{A}} \pm 0.02$ \\
\hline Sodium ion, $\mathrm{mmol} / \mathrm{L}$ & $152.9^{b} \pm 0.90$ & $152.4^{b} \pm 0.9$ & $155.6^{a} \pm 0.9$ \\
\hline Potassium ion, $\mathrm{mmol} / \mathrm{L}$ & $4.01^{B} \pm 0.08$ & $4.13^{B} \pm 0.07$ & $3.46^{\mathbf{A}} \pm 0.07$ \\
\hline Chloride ion, mmol/L & $120.1^{A} \pm 0.77$ & $116.2^{\mathrm{B}} \pm 0.72$ & $119.4^{A} \pm 0.72$ \\
\hline
\end{tabular}

a,b; A,B Within a column means with a common superscript did not differ at $P=0.05$ or 0.001 , respectively

The results demonstrate a significant difference in the leukocyte count between the three breeds, simultaneously with no differences between $\mathrm{Zk}$ and $\mathrm{Pb}$. Leghorn had the lowest percentage of lymphocytes and the highest percentage of HET, with the highest $\mathrm{H}$ : $\mathrm{L}$ ratio relative to the other breeds. In $\mathrm{Zk}$, the high level of lysozyme in comparison with $\mathrm{Pb}$ and $\mathrm{Lg}$ is noteworthy. There were significant differences between the breeds in the levels of $\mathrm{Na}, \mathrm{K}$, and $\mathrm{Cl}$ ions in blood serum (Table 3). These differences were observed between the $\mathrm{Lg}$ birds and the $\mathrm{Zk}$ and $\mathrm{Pb}$ breeds in $\mathrm{Na}+\mathrm{K}+$ ions. The highest $\mathrm{Na}+$ level was found in the $\mathrm{Lg}$, concurrently with the lowest $\mathrm{K}+$ value. There were no differences in the levels of $\mathrm{Na}+$ and $\mathrm{K}+$ ions between $\mathrm{Zk}$ and $\mathrm{Pb}$. The level of $\mathrm{Cl}$ - differed significantly between the breeds, with the lowest values of $\mathrm{Pb}$.

The research indicated that $\mathrm{Lg}$ differs in behaviour from $\mathrm{Zk}$ and $\mathrm{Pb}$. Leghorn birds were more excitable and more mobile during the MOFT test. They examined twice as many objects in the same time and moved around more intensively than the other breeds. This means that they explored their surroundings superficially and quickly, without showing much interest in the objects. Such behaviour was confirmation of results reported by Kozak et al. (2019a), who demonstrated the greatest emotional reactivity of the Lg breed.

It may be debated whether the behaviour of $\mathrm{Lg}$ hens is associated with the large-scale production of the breed as a result of the reaction correlated between performance and behavioural traits (RozempolskaRucińska et al., 2017) or whether the differences are associated with the white colour of feathers. White laying hens have been shown to be reactive and demonstrate an intense hormonal and behavioural response to stress compared with brown hens (Fraisse \& Cockrem, 2006; Ulitdehaag et al., 2011; de Haas et al., 2013; Pusch et al., 2018). 
Observation of the differences in behaviour of the hens was accompanied by analysis of their stress levels. The serum cortisol level is an indicator of strong but temporary emotional stimulation (Weimer et al., 2018). The level of this hormone rises sharply two to three minutes after the bird is caught as the body's response to the stress factor, and high individual variability is observed (Schwabl et al., 1991; Le Maho et al., 1992; Hood et al., 1998; Romero \& Reed, 2005). In the present study, there were no differences in the serum cortisol level between the breeds, which may indicate that the body's response to an acute stress factor is similar in all breeds. A more objective and reliable indicator of stress is the level of corticosterone in feathers, which is an indicator of long-term stress experienced by a bird in its lifetime (Bortolotti et al., 2008; Weimer et al., 2018). In this study, the lowest corticosterone level was noted in the feathers of the Zk hens. However, significant differences were found only between $\mathrm{Zk}$ and $\mathrm{Pb}$. Interestingly, there were no behavioural differences between $\mathrm{Zk}$ and $\mathrm{Pb}$, although the birds differed in the corticosterone level. However, behavioural reactions do not reflect stress (Cockrem, 2007). As in previous studies (Kozak et al., 2019a), the $\mathrm{Zk}, \mathrm{Pb}$, and $\mathrm{Lg}$ hens preferred different enrichments of the environment. Green-legged partridge were most often engaged in activities such as scratching. This may explain the reduced level of corticosterone in the Zk feathers (Table 3). The living environment, that is, keeping the hens in the floor system, satisfied the needs of Zk birds. The possibility of meeting emotional needs undoubtedly reduces stress (Marino, 2017).

However, conclusions about stress levels based solely on the amount of corticosterone in the feathers should be drawn carefully. For example, it is not certain whether the amount of deposited corticosterone is related to the colour of feathers, because the amount of cortisol in hair is associated with its colour (Heimbürge et al., 2019). For this reason, the study included indices of protein cell count. The count and proportions of leukocytes in blood are important indicators of the function of the immune system and the level of stress affecting the organism (Dhabhar, 2009). Glucocorticoids exert a wide range of effects on the body, for example on the immune system, water and electrolyte balance, and metabolism (Ajakaiye et al., 2010; Blas et al., 2007).

Therefore, assessment of the stress level can be based on white blood cell parameters, which include the count and proportions of various leukocyte forms, such as the $\mathrm{H}$ : L ratio (O'Brien et al., 2001; Lobato et al., 2005, Nadolski et al., 2006; Pusch et al., 2018). The analysis of the white blood cell parameters confirmed that the Zk hens had the lowest stress level. This was indicated mainly by the lowest $\mathrm{H}$ : $\mathrm{L}$ ratio and the highest lysozyme level. A decrease in the lysozyme concentration in the blood of birds can be observed in stressful situations, for example during immobilization (Fitko et al., 1992). This may be because Zk is one of the primitive breeds, which usually have lower stress indicators, better health, and greater plasticity of behaviour (Blas et al., 2007). At the same time, it may be related to the birds' living environment, which was best adapted to this breed. The birds were kept in a building with litter and, among the objects that diversified the environment, the Zk hens preferred the container filled with pellets, insect larvae, and chopped straw, and spent most of their time scratching and digging (Kozak et al., 2019a). The birds not only ate the feed, but scratched the ground and searched, satisfying one of their basic needs, which is curiosity (Panksep, 2005). In the other two breeds, completely different preferences were observed, which were unrelated to scratching the ground (Kozak et al., 2019a). These preferred behaviours may not be available to chickens in the conditions of a large farm. It could therefore be presumed that the inability to meet the needs of these breeds caused increased stress.

The highest white blood cell parameters that are indicative of stress were found in the Lg hens. These birds had the highest percentage of HET and the lowest level of lymphocytes. Lymphocyte levels are reduced in response to elevated stress (Dhabhar, 2009). In turn, the number of heterophils increases in response not only to pathogens (bacteria, fungi), but also to stress (Maxwell \& Robertson, 1998; Harmon, 1998), with a simultaneous decrease in the number of lymphocytes (Feldman et al., 2000, Bonier et al., 2007; Krams et al., 2011). The heterophil to lymphocyte ratio is considered a reliable indicator of the stress level in birds, primarily making it possible to determine the body's response to stress caused by the environment (Ruiz et al., 2002; Davis et al., 2004; Sergent et al., 2004; Ardia \& Schat, 2008; Davis et al., 2008). The values of this parameter indicate that the $\mathrm{Lg}$ chickens had the highest level of stress. It may be surprising that the glucocorticoid response was not higher in the Lg hens than in the other breeds, while the elevated biochemical parameters indicated stress. However, the $\mathrm{H}: \mathrm{L}$ ratio is a more reliable indicator than the corticosterone level (Maxwell, 1993). The increased level of stress in this breed was confirmed by the other indicators. Compared with Zk, the Lg hens had a significantly lower lysozyme level, which decreases in stress conditions (Fitko et al., 1992), and a higher concentration of $\mathrm{Na}^{+}$ions and a lower concentration of $\mathrm{K}^{+}$ ions. These parameters and specifically the water and electrolyte balance are influenced significantly by the cortisol level, which causes increased reabsorption of sodium and water in renal tubules and increased excretion of potassium in urine (Li et al., 2016; del Liján et al., 2016).

Leghorns had a substantially higher level of monocytes than the other breeds. The monocyte count in the blood may increase because of the action of glucocorticoids (Sapolsky et al., 2000), which confirms that 
$\mathrm{Lg}$ birds were more stressed. The high total leukocyte count relative to the other two breeds may be surprising. However, the leukocyte count need not be associated with stimulation of immune responses, but with the number of eosinophils, the share of which in the leukogram increases in stressful situations (Apanius, 1998; Dhabhar, 2009). In the Lg breed, the eosinophil level was high relative to Zk and Pb, which confirms the increased level of stress in this breed. This was confirmed by the physiological and behavioural reactions noted in the MOFT test. The probability of reactions such as preening was significantly higher in $\mathrm{Lg}$ than in $\mathrm{Zk}$ and $\mathrm{Pb}$. Previous studies have shown that birds that perform such activities have an elevated level of stress, and these reactions can be regarded as behaviours that relieve emotional tension (Kozak et al., 2019a). Grooming behaviours in animals serve mainly to maintain hygiene, but they may appear to be reducing agitation and promoting relaxation (Spruijt et al., 1992). This is confirmed because the frequency of grooming behaviour in birds increases with the frequency of conflict situations (Manning \& Dawkins, 1992). Moreover, in various animal species grooming is believed to be more common in a dull environment (Berthelsen \& Hansen, 1999; Hansen \& Berthelsen, 2000). Grooming behaviours may appear in expectation of positive events (Zimmerman et al., 2011). However, this does not exclude a high level of excitement, which does not need to be associated with negative emotions. Given these observations, it can be assumed that a significant increase in the likelihood of activities such as shaking out the feathers or grooming in $\mathrm{Lg}$ is associated with strong emotional arousal in these birds and confirms their much higher reactivity relative to $\mathrm{Zk}$ and $\mathrm{Pb}$. In addition, the probability of defecation was significantly higher in $\mathrm{Lg}$, which confirms their increased excitability (Zimmerman et al., 2011).

The Leghorn breed exhibited high excitability and mobility. Increased excitability was manifested by quick movement from place to place, superficial and chaotic exploration of the environment, and physiological and behavioural activities such as increased defecation and preening. The Leghorn hens were characterized by excessive excitability with simultaneously increased levels of stress based on the white blood cell count.

The Green-legged partridge breed exhibited the lowest stress rates. The most important need of this breed, that is, to scratch and dig (Kozak et al., 2019a) was satisfied in the farming conditions. It should be investigated whether intensive selection for better performance traits can indirectly affect hens by modifying their behaviour and consequently increase the stress indicators.

\section{Conclusions}

Birds of different breeds vary significantly in their stress levels, despite the same environmental conditions. The lowest levels of stress indicators were observed in the breed whose behavioural needs were best fulfilled in their environment. Increased stress levels were detected in highly excitable hens, which could not fully satisfy the behavioural needs under the conditions of the MOFT. This implies that hens' preferences have to be determined first to supply them with optimum environmental conditions for improved welfare.

\section{Acknowledgements}

The authors are grateful to the staff of the stud farm for their help and understanding. We also thank students for their help during test sessions.

\section{Authors' Contributions}

All authors participated in the research, and read and approved the final manuscript.

\section{Conflict of Interest Declaration}

We confirm that there are no known conflicts of interest associated with this publication and there has been no significant financial support for this work that could have influenced its outcome.

\section{References}

Ajakaiye, J.J., Joseph, O., Ayo, J.A. \& Ojo, S.A., 2010. Effects of heat stress on some blood parameters and egg production of Shika Brown layer chickens transported by road. Biol. Res. 43, 183-189.

Apanius, V., 1998. Stress and immune defence. Adv. Stud. Behav. 27, 133-153.

Ardia, D.R. \& Schat, K.A., 2008. Ecoimmunology. In: F.B. Davison Kaspers \& K.A. Schat (eds). Avian Immunology. Elsevier Academic Press, London, pp. 421-441.

Berthelsen, H. \& Hansen, L.T., 1999. The effect of hay on the behavior of caged rabbits (Oryctolagus cuniculus). Anim. Welfare 8,149-57.

Blas, J., Bortolotti, G.R., Tella, J.L., Baos, R. \& Marchant, T.A., 2007. Stress response during development predicts fitness in a wild, long-lived bird. Proc. Natl. Acad. Sci. USA 104, 8880-8884.

Bonier, F., Martin, P.R., Sheldon, K.S., Jensen, J.P., Foltz, S.L. \& Wingfield, J.C., 2007. Sex specific consequences of life in the city. Behav. Ecol. 18, 121-129.

Bortolotti, G.R., Marchant, T.A., Blas, J. \& German, T., 2008. Corticosterone in feathers is a long-term, integrated measure of avian stress physiology. Funct. Ecol. 22(3), 494-500. 
Cockrem, J.F., 2007. Stress, corticosterone responses and avian personalities. J. Ornithol. 148, 169-178.

Davis, A.K., Cook, K.C. \& Altizer, S., 2004. Leukocyte profiles in wild house finches with and without mycoplasmal conjunctivitis, a recently emerged bacterial disease. Eco. Health. 1, 362- 373.

Davis, A.K., Maney, D.L. \& Maerz, J.C., 2008. The use of leukocyte profiles to measure stress in vertebrates: A review for ecologists. Funct. Ecol. 22, 760-772.

de Haas, E.N., Kemp, B., Bolhuis, J.E., Groothuis, T. \& Rodenburg, T.B., 2013. Fear, stress, and feather pecking in commercial white and brown laying hen parent-stock flocks and their relationships with production parameters. Poult. Sci. 92, 2259-2269.

del Liján, A.N., Cardoso, E., Arregger, A., Budd, D., Zucchini, A.E. \& Contreras, L.N., 2016. Dynamics of salivary cortisol in chronic kidney disease patients at stages 1 through 4. Clin. Endocrinol. 85(2), 313-319.

Dhabhar, F.S., 2009. Enhancing versus suppressive effects of stress on immune function: Implications for Immunoprotection and Immunopathology. Neuroimmunomodulat. 16, 300-317.

Feldman, B., Zinki, J. \& Jain, N., 2000. Schalm's veterinary haematology. 5th edition. Lippincott \& Wilkins, Philadelphia. pp. 1120-1124.

Fitko, R.K., Jakubowski, E., Roszko, Zieliński, H. \& Potrzuska, I., 1992. The level of corticosterone and immune parameters in chicken in immobilization stress and after application of immunomodulators (in Polish). Medicine Vet. 48, 298-300.

Fraisse, F. \& Cockrem, J.F., 2006. Corticosterone and fear behaviour in white and brown caged laying hens. Brit. Poult. Sci. 47, 110-119.

Freire, R., Van Dort, S. \& Rogers, L.J., 2006. Pre- and post-hatching effects of corticosterone treatment on behavior of the domestic chick. Horm. Behav. 49, 157-165.

Hansen, L.T. \& Berthelsen, H., 2000. The effect of environmental enrichment on the behavior of caged rabbits (Oryctolagus cuniculus). Appl. Anim. Behav. Sci. 68,163-78.

Harmon, B.G. 1998. Avian heterophils in inflammation and disease resistance. Poult. Sci. 77, 972-977.

Heimbürge, S., Kanitz, E. \& Otten, W., 2019. The use of hair cortisol for the assessment of stress in animals. Gen. Comp. Endocrinol. 270, 10-17.

Hood, L.C., Boersma, P.D. \& Wingfield, J.C., 1998. The adrenocortical response to stress in incubating Magellanic Penguins (Spheniscus magellunicus). Auk. 115, 76-84.

Janczak, A.M., Torjesen, P., Palme, R. \& Bakken, M., 2007. Effects of stress in hens on the behaviour of their offspring. Appl. Anim. Behav. Sci. 107, 66-77.

Janczak, A.M., Braastad, B.O. \& Bakken, M., 2006. Behavioural effects of embryonic exposure to corticosterone in chickens. Appl. Anim. Behav. Sci. 96, 69-82.

Kozak, A., Kasperek, K., Zięba, G. \& Rozempolska-Rucińska, I., 2019a. Variability of laying hen behaviour depending on the breed. Asian-Australas. J. Anim. Sci. 32(7), 1062-1068.

Kozak, A., Rozempolska-Rucińska, I., Kasperek, K. \& Bownik, A., 2019b. Level of stress in relation to emotional reactivity of hens. Ital. J. Anim. Sci. 18, 1252-1258.

Kozak, A., Kasperek, K., Zięba, G. \& Rozempolska-Rucińska, I., 2019c. Potential of application of a modified open-field test for selection of laying hens. Anim. Sci. Pap. Rep. 37 (4), 333-343.

Krams, I., Cîrule, D., Krama, T. \& Vrublevska, J., 2011. Extremely low ambient temperature affects haematological parameters and body condition in wintering great tits (Parus major). J. Ornithol. 152, 889-895.

Le Maho, Y., Karmann, H., Briot, D., Handrich, Y., Robin, J.P., Mioskowski, E., Cherel, Y. \& Farni, J., 1992. Stress in birds due to routine handling and a technique to avoid it. Am. J. Physiol. 263, 775-781.

Li, X., Xiang, X., Hu, J., Goswami, R., Yang, S., Zhang, A., Wang, Y., Li, Q. \& Bi, X., 2016. Association between serum cortisol and chronic kidney disease in patients with essential hypertension. Kidney Blood Press Res. 41, 384-391.

Lindqvist, C., Janczak, A.M., Natt, D., Baranowska, I., Lindqvist, N., Wichman, A., Lundeberg, J., Lindberg, J., Torjesen, P.A. \& Jensen, P., 2007. Transmission of stress-induced learning impairment and associated brain gene expression from parents to offspring in chickens. PLoS ONE 2, 364.

Lobato, E., Moreno, J., Merino, S., Sanz, J.J., Arriero, E., 2005. Haematological variables are good predictors of recruitment in nestling pied flycatchers (Ficedulahypoleuca. Ecosci). 12, 27-34.

Manning, A. \& Dawkins, M., 1992. An introduction to animal behavior. Cambridge University Press, Cambridge. pp. $72-$ 85.

Marino, L., 2017. Thinking chickens: A review of cognition, emotion, and behavior in the domestic chicken. Anim. Cogn. 20, 127-147.

Maxwell, M.H., 1993. Avian blood leucocyte responses to stress. World Poult. Sci. J. 49, 34-43.

Maxwell, M.H. \& Robertson G.W., 1998. The avian heterophil leucocyte: A review. World Poult. Sci. J. 54, 155-178.

Nadolski, J., Skwarska, J., Kaliński, A., Bańbura, M., Śnieguła, R. \& Bańbura, J., 2006. Blood parameters as consistent predictors of nestling performance in great tit (Parus major) in the wild. Comp. Biochem. Physiol. 143, 50-54.

O'Brien, E.L., Morriso, B. \& Johnson, L.S., 2001. Assessing the effects of haematophagousecto-parasites on the health of nestling birds: Haematocrit vs. haemoglobin levels in house wrens parasitized by blow fly larvae. J. Avian Biol. $32,73-76$

Oyewale, J.O., 1992. Changes in osmotic resistance of erythrocytes of cattle, pigs, rats, and rabbits during variations in temperature and $\mathrm{pH}$. J. Vet. Med. 39, 98-104.

Panksepp, J., 2005. Affective consciousness: Core emotional feelings in animals and humans. Conscious Cogn. 14, 3080.

Pusch, E.A., Bentz, A.B., Becker, D.J. \& Navara, K.J., 2018. Behavioral phenotype predicts physiological responses to chronic stress in proactive and reactive birds. Gen. Comp. Endocr. 255, 71-77. 
Regulation of the Minister of Agriculture and Rural on the Protection of Animals. Journal of Laws of 2003 No. 106, item 1002.

Rodenburg, T.B., Buitenhuis, A.J., Ask, B., Uitdehaag, K.A., Koene, P., Van der Poel, J.J. \& Bovenhuis, H., 2004. Genetic and phenotypic correlations between feather pecking and open-field response in laying hens at two different ages. Behav. Genet. 34, 407-15.

Romeis, B., 1989. Untersuchung des Blutes und des blutbildenden Knochenmarks. In: P. Bock (ed). Mikroskopische Technik. Urban \& Schwarzenberg, Munchen, 475.

Romero, L.M. \& Reed, J.M., 2005. Collecting baseline corticosterone samples in the field: Is under 3 min good enough? Comp. Biochem. Physiol. 140, 73-79.

Rozempolska-Rucińska, I., Zięba, G., Kibała, L., Próchniak, T. \& Łukaszewicz, M., 2017. Genetic correlations between behavioural responses and performance traits in laying hens. Asian-Australas. J. Anim. Sci. 30(12), 1674-1678.

Rozempolska-Rucińska, I., Zięba, G. \& Łukaszewicz, M., 2009. Hatchability traits as selection criteria in breeding of laying hens. Arch Geflügelkd. 73(4), 263-267.

Rozempolska-Rucińska, I., Zięba, G., Łukaszewicz, M., Ciechońska, M., Witkowski, A. \& Ślaska, B., 2011. Egg specific gravity in improvement of hatchability in laying hens. J. Anim. Feed. Sci. 20, 84-92.

Ruiz, G., Rosenmann, M., Novoa, F.F. \& Sabat, P., 2002. Hematological parameters and stress index in rufous-collared sparrows dwelling in urban environments. Condor 104, 162-166.

Sapolsky, R.M., Romero, L.M. \& Munck, A.U., 2000. How do glucocorticoids influence stress responses? Integrating permissive, suppressive, stimulatory, and preparative actions. Endocr. Rev. 21, 55-89.

Schwabl, H., Bairlein, F. \& Gwinner, E., 1991. Basal and stress-induced corticosterone levels of garden warblers, Sylvia borin, during migration. J. Comp. Physiol. 161, 576-580.

Sergent, N., Rogers, T. \& Cunningham, M., 2004. Influence of biological and ecological factors on hematological values in wild Little Penguins, Eudyptula minor. Comp. Biochem. Physiol. 138, 333-339.

Siwicki, A.K. \& Anderson, D.P. 1993. Nonspecific defence mechanisms assay in fish. II. Potential killing activity of neutrophils and macrophages, lysozyme activity in serum and organs, and total immunoglobulin (lg) level in serum. Fish Diseases Diagn. Prevent. Methods. FAO-Project CGP/INT/526/JAN, FFI Olsztyn. pp. 105-112.

Spruijt, B.M., Van Hooff, J.A. \& Gispen, W.H. 1992. Ethology and neurobiology of grooming behavior. Physiol. Rev. 72 , 825-852.

Thiruvenkaden, A.K., Panneerselvam, S. \& Prabakaran, R., 2010. Layer breeding strategies: An overview. World's Poult. Sci. J. 66, 477-501.

Uitdehaag, K.A., Rodenburg, T.B., Van Reenen, C.G., Koopmanschap, R.E., De Vries, R.G., Engel, B., Buist. W.G., Komen, H. \& Bolhuis, J.E., 2011. Effects of genetic origin and social environment on behavioral response to manual restraint and monoamine functioning in laying hens. Poult. Sci. 90, 1629-1636.

Weimer, S.L., Scanes, C.G., Mauromoustakos, A., Christensen, K.D. \& Vizzier-Thaxton, Y., 2018. An evaluation of methods for measuring stress in broiler chickens. Poult. Sci. 97(10), 3381-3389.

Zimmerman, P.H., Buijs, S.A.F., Bolhuis, J.E. \& Keeling, L.J., 2011. Behaviour of domestic fowl in anticipation of positive and negative stimuli. Anim. Behav. 81, 569. 